\title{
Corpos dissidentes em associação e reconhecimento
}

\author{
Marcos Sardá Vieira \\ Universidade Federal da Fronteira Sul, Brasil \\ marcosarda@gmail.com
}

\section{Resumo}

Nesse artigo analiso a necessária condição de associação entre corpos e objetos de consumo como modo de tornar viável a representação de grupos dissidentes da cisheteronormatividade. Através de análise fenomenológica a partir de fatos e eventos públicos em Berlim, problematizo a condição de precariedade de corpos e identidades dissidentes quando individualizados pelas relações com outros sujeitos, ou mesmo, quando desassociados de objetos no âmbito estético da cultura material e urbana advindos da Modernidade. A representação dissidente na esfera pública costuma se tornar inviável devido à condição hegemônica de desejos heterossexuais. Porém, quando essa multidão de corpos dissidentes associa-se com objetos e bens de consumo, abre-se um campo tênue de possíveis negociações e visibilidades. Assim, além da conformação de assembleia entre corpos dissidentes para tornar visível suas representações sociais, essa associação costuma estar vinculada à estética da indústria cultural contemporânea como meio de negociar suas aparições através de seus corpos fetichizados, envolvendo prazer e lucro.

Palavras-chave: corpos, dissidência, associação, cidade. 


\title{
Dissident bodies in association and recognition
}

\begin{abstract}
In this article I analyze the necessary condition of association between bodies and objects of consumption as a way to make viable the representation of groups dissidents from cisheteronormativity. Through phenomenological analysis based on facts and public events in Berlin, I problematize the precarious condition of dissident bodies and identities when individualized by relations with other subjects, or even when disassociated from objects in the aesthetic scope of material and urban culture arising from Modernity. Dissident representation in the public sphere tends to become unviable due to the hegemonic condition of heterosexual desires. However, when this multitude of dissident bodies associates with objects and consumer goods, a tenuous field of possible negotiations and visibilities opens up. Thus, in addition to the conformation of assemblies between dissident bodies to make their social representations visible, this association is usually linked to the aesthetics of the contemporary cultural industry as a means of negotiating their appearances through their fetishized bodies, involving pleasure and profit.
\end{abstract}

Keywords: bodies, dissent, association, city.

Fecha de recepción: 30 de septiembre de 2019.

Fecha de aprobación: 15 de marzo de 2020. 


\section{Introdução}

Apesar das representações públicas e urbanas da atualidade seguirem o modelo estético da razão técnica e atenderem, majoritariamente, aos desejos cisheterossexuais masculinos, é possível destacar alguns fenômenos que surgem para desviar nossa condição de existência dessa estrutura de alienação e qualificar as ações humanas como obras da arte (Argan, 2005).

Nesse sentido, considero existirem condições tênues para que certos fenômenos sejam julgados como positivos ou negativos diante de valores (estéticos e morais) pautados pela viabilidade técnica e econômica preponderante (Benjamin, 2000). Assim, na medida em que algumas representações de corpos e identidades queer rompem com a noção de sensibilidade singular e tornam-se compatíveis com o senso estético da indústria cultural, surge a possibilidade de valorização de seus corpos e performatividades em associação com a ética da cultura material predominante (Butler, 2018; Leite, 2014). Entretanto, quais os limites dessa associação para que sejam mantidas as condições de autenticidade sem o risco da normalização de comportamentos?

Através da experiência de análise fenomenológica a partir de eventos sociais ligados às subculturas LGBTI + da atualidade, o objetivo desse artigo é refletir sobre a representação de corpos e identidades dissidentes diante da condição ambígua de existência, ao transitar entre a estética da reprodução técnica e a partilha do sensível na busca pela autenticidade.

Com esse propósito, analiso ao longo do artigo a performatividade coletiva de corpos em aliança para a realização do evento Folsom em Berlim, na manifestação coletiva de fetiches e práticas sexuais associadas com o consumo de roupas e acessórios referentes a essa subcultura gay berlinense. Essa manifestação coletiva nas ruas de Schöneberg (bairro berlinense) também corresponde às festas privadas (relativas ao evento) onde os corpos são usurpados como suporte de fantasias e acessórios de fetiche para satisfazer desejos sexuais entre os participantes e, ao mesmo tempo, gerando expectativa de lucratividade de seus organizadores. Ao considerar o efeito dessa manifestação de corpos dissidentes também associo esses rituais sexuais e coletivos com a estética de prazeres carnais, exemplificada pela pintura $\mathrm{O}$ jardim das delícias terrenas, de Hieronymus Bosch em um contexto de controle moral distinto da modernidade, onde a obra de arte mantinha o seu papel metafísico predominante.

$\mathrm{Na}$ análise interdisciplinar deste artigo considero que a noção convencional da cidade contemporânea define-se, majoritariamente, como ambiente de regulamentação social para os 
comportamentos, identidades e as manifestações artísticas com o intuito de atender aos interesses econômicos globalizados. Por isso, essa estrutura urbana pautada pela cisheterossexualidade masculina define restrições para a expressão social das subculturas outsiders com suas práticas sexuais, envolvendo fetiches e desejos dissidentes. Nessa estrutura de controle, qualquer desvio particular dessas condutas estabelece o limite para a constituição do corpo como obra de arte, ou mesmo, o limite da arte enquanto manifestação criativa e original para compor outras estéticas e éticas de existência.

Por fim, considero que a singularidade e a expressão do sujeito-corpo sexuado encontram-se mais exposto à precarização da vida quando desprovido de alegorias e objetos de pertencimento, ou mesmo, quando desvinculado da multidão queer, presente nas ruas e nos movimentos sociais (Preciado, 2011). Assim, quando corpos dissidentes do contexto urbano predominante apresentam-se reunidos em eventos públicos, eles precisam negociar suas representações por meio de práticas de consumo, principalmente, na hipersexualização da imagem e na exploração consentida de seus corpos como objetos de fetiche e, em decorrência, como fonte de prazer e lucro.

\section{Noção de corpos em aliança}

No livro "Corpos em aliança e a política das ruas" Judith Butler (2018) nos faz refletir sobre a importância dos movimentos sociais da atualidade, na conquista do espaço público e na própria formação de modos de performatividade coletiva constituídos enquanto unidade. A autora expõe seus argumentos a partir da aliança mantida entre sujeitos plurais (com diferentes desejos, identidades e representações), que se reúnem para contestar o estado comum de suas precariedades socioculturais sob os efeitos da regulamentação social, do controle policial e da opressão neoliberal sobre as políticas dos direitos humanos e os corpos miscigenados, também marcados pela dissidência de gênero e sexualidades.

Por mais que autores como Foucault (2008), Arendt (2007) e Agamben (2007) tenham nos apresentado os efeitos corrosivos do biopoder e dos hábitos de consumo como dispositivos de controle e condicionamento da população urbana, segundo Butler (2018) os movimentos sociais em espaços públicos na atualidade parecem requerer novas estratégias de resistência por parte dos manifestantes quando reunidos por interesses de aliança política.

De acordo com Butler (2018:86) o espaço de aparecimento do corpo, na ação que emerge do “entre”, não é um aspecto adquirido apenas pela arquitetura, seguindo sua análise para a 
noção de espaço público a partir de Hannah Arendt. No caso, o espaço de aparecimento sempre se constitui pela modalidade de ação e fala, precedendo as formas possíveis de organizar o domínio público em ações plurais. Espaço e ações, nesse sentido, estão imbricados na definição do espaço de aparecimento. Assim, a autora estadunidense questiona a própria constituição da pluralidade que age, quais seus suportes materiais, como se forma e quem participa.

Por mais que o corpo-sujeito não corresponda à performatividade, expressão e identidade cisheterossexual, é comum sua vinculação com a realidade material e imagética em associação com objetos de valor econômico, como roupas, veículos, arquitetura e a própria constituição física da cidade. Observei esses aspectos acompanhando o cotidiano da comunidade do bairro LGBTI+ de Schöneberg em Berlim, no ano de 2016, para constatar a vinculação dessas subculturas de sexualidades e fetiches com o contexto material onde estão inseridas.

Caminhando pelas ruas do bairro de Schöneberg e, principalmente, nos encontros promovidos pelos estabelecimentos comerciais, notei que as imagens dos corpos, principalmente, masculinos eram permeadas por estilos de roupas, penteados, tatuagens e acessórios variados, na indicação de identidades, que vão sendo incorporadas pelos grupos e misturadas de acordo com os interesses particulares de indivíduos, como se esses atributos materiais reforçassem (e tornassem verídica) uma identidade que não pode ser mantida apenas pelos atributos fisiológicos do corpo. É neste sentido que interpreto Donna Haraway (2009) ao conceber o termo do sujeito ciborgue, quando o corpo natural se faz híbrido com máquinas, tecnologias e objetos de luxo e ultrapassa sua condição estigmatizada pelas feições do corpo natural e ordinário. De maneira similar Preciado (2014) considera estes objetos ligados ao sujeito como próteses corporais, que constroem a imagem do sujeito-corpo sexualizado e como resultado do arranjo com sofisticadas tecnologias.

Essa estratégia de descentrar a cultura material hegemônica da cisheteronormatividade foi enfatizada quando tive a oportunidade de visitar o evento Folsom Street Fair, congregando uma das subculturas mais presentes na representação homossexual berlinense em Schöneberg. Trata-se de um evento anual de fetiche sadomasoquista (escravidão, disciplina, dominância e submissão/BDSM) e da subcultura leather (no uso de roupas e acessórios de couro) como parte da semana Folsom Europe. Em sua $13^{a}$ edição este é o maior evento de fetiche gay europeu, movimentando grande contingente de público em Berlim. Esta reunião congrega praticantes, curiosos e comerciantes no espaço público de toda a cidade. É um momento de 
encontro, exposição de corpos e performatividades a ser considerado como movimento de subcultura vinculado a roupas, acessórios, comportamentos e discursos na expressão da identidade do grupo e na representação de um mercado consumidor desses artigos de vestuário, objetos de práticas sexuais, lazer noturno, hotelaria e conferências ligadas aos (sub)grupos e temáticas do evento.

Na diferenciação da superfície dos corpos representativos do Folsom, uma das características que mais definem o evento são as roupas e acessórios específicos utilizados como indumentária para identificar o enquadramento dos estilos B\&D (bondage e disciplina), D\&S (dominação e submissão) e S\&M (sadismo e masoquismo), resguardando a nudez e a sexualidade em determinadas partes do corpo. São cintos e suspensórios de couro, calças abertas entre as pernas, botinas e máscaras com tubos ou orifícios, que indicam a posição (roll) de cada pessoa no desempenho da prática sexual. Como se o vestuário, além de demarcar a alegoria do BDSM no corpo do praticante, também definisse dentro destes códigos o interesse de cada pessoa como receptor e/ou doador no comportamento e ações sexualizadas.

De maneira geral, o evento caracteriza-se como manifestação da subcultura gay e cisgênero, diante da presença predominante de corpos masculinos e homossexuais e definindo suas alianças, principalmente, pela comunicação visual através do vestuário. Desse modo, a intenção principal do evento parece estar voltada ao lazer e consumo, porém, é possível considerar o caráter de resistência política desses corpos em aliança ao reafirmarem com regularidade suas representações e desejos dissidentes da heteronormatividade, mesmo sem o caráter contestatório imediato dessa performatividade coletiva.

Aqui, destaco que nossa condição de ser e aparecer para o outro está vinculada ao espaço definido entre as presenças corporais. Ou seja, somos apoiados pela nossa aparência no espaço ou por sua organização espacial para garantir nosso aparecimento. Entretanto, não é possível considerar apenas nossa aparição como fenômeno visual. Nossas vozes e performatividades também representam uma condição de enfrentamento e reconhecimento. $\mathrm{Na}$ medida em que o corpo se torna disponível para o reconhecimento público é perdido o senso de antecipação e o controle sobre essa perspectiva de aparição. Apesar desse limite de percepção do reconhecimento do próprio corpo pelo outro, cada corpo participa no deslocamento dessa perspectiva de participação conjunta ao estabelecer uma performatividade que constitui o exercício de ação, mesmo sem estabelecer (e controlar) o espaço do próprio 
aparecimento. É uma ação que se estabelece pelo espaço entre os corpos, que tanto vincula quanto diferencia (Butler, 2018; Bento, 2006). Desse modo, em uma escala mais ampla, é intrigante considerar o efeito contestatório do evento Folson no contraste com o contexto urbano e cisheteronormativo de Berlim para compreender o porquê de sua viabilidade representativa e regularidade anual.

Ao visitar o evento público em uma tarde de sábado acompanhei a multidão queer na (rua) Fuggerstraße e Welserstraße, nas imediações dos bares Prinzknecht, Dreizehn e Woof. Predominavam corpos e representações masculinas vestindo os mais variados tipos de roupas e acessórios de fetiche leather, rubber e uniform, vinculados ao uso de materiais como couro, metal, vinil e plástico. Roupas extravagantes, penteados radicais e punks, muita relação dicotômica entre dominação e submissão como associação direta do prazer (sexual) com a agressividade e a dor física. A presença de corpos e expressões femininas parecia resguardada no evento de rua. Boa parte das mulheres e das identidades femininas utilizavam roupas sedutoras no estilo leather e vestidos de látex. Dado o caráter homossexual do evento de práticas BDSM, não foi surpresa encontrar grupos segmentados entre homens e mulheres. Mas a presença dos homens foi majoritária, principalmente, nas demonstrações envolvendo as práticas no uso de chicotes, mordaças, correntes, algemas, coleiras entre outros elementos expostos e disponíveis ao consumo e apreciação visual.

Acredito ser nessa combinação representativa que o evento define-se como ação coletiva e política ao ocupar um espaço público e promover ruídos com as aparências hegemônicas da moralidade predominante na cidade. Por isso, torna-se fundamental negociar essas ações e comportamentos temporários no espaço público. Assim, a realização do Folsom predispõe à delimitação da área urbana com cones e faixas, filtrando o acesso aleatório do público, mas sem impedir a passagem de pessoas adultas. O caráter outsider do evento era nítido em suas fronteiras territoriais, onde as entradas e saídas eram monitoradas por um grupo de dragqueens (Tunte) chamadas Sisters Conclave Berlin, que distribuíam folders e coletavam donativos para campanhas em favor da comunidade LGBT.

Similar à Queer Week (evento de uma semana, que antecede a Parada Gay de Berlim), a Folsom Street Fair também estimula o movimento de público nos estabelecimentos comerciais de Schöneberg, principalmente, no entorno imediato. As lojas de artigos de fetiche leather e BDSM, os bares, restaurantes e hotéis mantêm esta rede de conexões materiais com o espaço público. Exemplo disso era o bar popular Prinzknecht, que estava com suas portas de 
vidro totalmente abertas e com as mesas retangulares de madeira totalmente ocupadas na calçada. A fachada principal do bar, com grandes portas de vidro, costuma manter uma única entrada de controle para destacar o ambiente intimista do interior. No inverno esse efeito (de ambiente fechado e acolhedor) é um atrativo fundamental para o estabelecimento. Durante o evento Folsom 2016, entretanto, o controle de entradas e saídas entre o bar e a rua tornou-se desnecessário. Todas as portas estavam abertas e o fluxo de pessoas era tão intenso que a multidão se aglomerava nas passagens internas do bar, que tem uma ampla área de balcão no espaço central principal da edificação. Todos os compartimentos estavam lotados. Atravessando o espaço principal do bar para chegar ao banheiro era necessário ultrapassar a aglomeração de corpos em todas as circulações internas, principalmente, devido ao acesso para a área cruising, na última porta ao fundo do banheiro, no acesso para o subsolo. Apesar de não haver empurrões e confrontos dentro do bar, a aglomeração para o acesso ao subsolo (na área cruising) denotava a mesma sensação claustrofóbica de outros bares durante o evento Queer Week, como se a multidão da rua precisasse recorrer ao ambiente escuro e confinado para dar vazão aos prazeres sexuais marcados pelo ciclo do encontro coletivo. Porém, esses espaços reservados não se limitaram aos bares do bairro Schöneberg.

Entre as principais festas vinculadas oficialmente à semana Folsom Europe 2016 estava a Pig, que congrega a programação do Folsom e aconteceu na noite desse mesmo sábado, 10 de setembro. Com o patrocínio de marcas de cerveja, loja de roupas BDSM, bares e revistas, a festa Pig estava locada no amplo espaço do Alte Münze Berlin, um complexo de amplos prédios antigos à margem do rio Spree e próximo da estação de metrô Klosterstraße. Com acesso restrito ao público masculino, o local é todo adaptado para criar um cenário propício para o lazer noturno, com bares, pistas de dança e iluminação programada, assim como para a prática sexual através de ambientes cruising e amplos espaços para a instalação de objetos e móveis específicos onde se aglomeravam corpos em práticas coletivas de sexo, voyeurismo, torturas consentidas e desvinculação total com a realidade fora dali. A iluminação dos corredores e da pista da dança, somada ao aspecto de abandono das superfícies internas do prédio, caracterizava um cenário de precariedades. No ambiente mais amplo de práticas sexuais as luzes acendiam eventualmente, dando chance para os corpos reconhecerem suas posições entre outros corpos antes da penumbra e escuridão tomarem conta novamente. Apesar da música promovida por DJ's nas pistas de dança, os gritos e gemidos predominavam na acústica do espaço criado para estimular o prazer sexual. Vários ambientes segmentados por cortinas de plantas artificiais separavam os equipamentos de apoio, como camas, barras 
cruzadas para prender os corpos, mesas e colchões. Outros ambientes menores dentro do edifício eram distribuídos pelos corredores, onde se instalavam outros equipamentos como mesas ginecológicas e jaulas, todos estes objetos e superfícies agregando significados específicos para as práticas e contatos corporais, que se renovavam em cada ciclo de orgasmos e prazeres. Era como uma grande catarse coletiva que tinha o orgasmo como ápice do prazer imanente e o corpo como elemento de descobertas alheias no limite da vulnerabilidade.

Por ser um ambiente mais intimista e apresentar um cenário mais completo para a interação do público com os objetos de apoio às práticas sexuais BDSM, o clima da festa é intenso na relação do sexo com a dor e a agressividade. Na maior parte, os corpos estavam vestidos com suas alegorias relativas ao BDSM e leather. Para preparar esta caracterização havia uma concentração de pessoas no hall de entrada, que se preparavam com suas indumentárias antes de entrar na festa ou para resgatar a roupa à paisana no deslocamento ordinário da rua, o que definiu um espaço apropriado com armários, bancos e guarda-volumes. Muitos homens se despiam totalmente para entrar na penumbra da festa, vestindo apenas sapatos ou botinas. Era perceptível não haver regras de como se vestir para entrar na festa, apesar das roupas e acessórios BDSM e leather estabelecerem uma diferença no grau de inclusão e participação do corpo para se tornar objeto de fetiche. Corpos malhados, mais velhos, mais novos, morenos, brancos, tatuados, corpos com várias fisionomias vestiam suas fantasias e acessórios para viver o prazer carnal intenso e compartilhado. Ao mesmo tempo em que o vestuário e acessório BDSM sinaliza a unidade do grupo, a maneira como cada pessoa combina sua indumentária também define suas preferências e atuações sexuais entre dominadores e dominados. Mesmo quando as pessoas não se limitam a estes papéis estabelecidos pelas alegorias, as peças do vestuário orientam estas zonas de interesse ressaltando ou escondendo partes do corpo. Nem todas as caracterizações são nítidas de uma intepretação dicotômica, mas é possível notar a existência de uma simbiose entre a produção destes acessórios e a incorporação desses significados na performatividade dos usuários. Por exemplo, o uso da máscara de vinil, totalmente rente ao rosto, tampando os olhos, as orelhas e deixando apenas um orifício na boca representa um uniforme e indica a aptidão ao sujeito passivo que promove o sexo oral ao(s) parceiro(s). Neste caso, os objetos, na alegoria de roupas e acessórios, delimitam um caráter estético e funcional para a performatividade. Como se tais objetos promovessem a comunicação não verbal em associação com os olhares e comportamentos na maneira como o sujeito se insere nesta linguagem corporal. 
O clima da festa é tenso na representação de fetiches, práticas sexuais, roupas pesadas e escuras e o teor de agressividade das práticas sexuais reverbera na acústica no ambiente confinado. O som do chicote estalando em algum corpo, a presença de corpos sendo presos em bancos/cadeiras específicas para serem golpeados com cinto de couro e as práticas de fisting são representações impactantes, associando prazer e dor em um processo que se repete como identidade; mas também criativo pelos agenciamentos permitidos no limite de cada corpo e da relação extrema de confiança entre os parceiros. O que torna marcante a relação do sujeito com o objeto, neste caso, é a aparência decadente de alguns corpos, que extrapolam os limites de integridade do organismo na busca de prazer, sendo marcados pela tortura agenciada e recorrente de práticas sexuais intermediadas por acessórios e instalações de materiais inertes, como elementos que orientam a caracterização do fetiche.

\section{Estética do corpo sexuado}

Na criatividade associada às práticas e fantasias sexuais presentes no Folsom e na festa Pig, será possível estabelecer uma estética do prazer associado à sexualidade? Por mais que os corpos e identidades presentes nesses eventos explorem suas potencialidades performativas pelas práticas sexuais em grupo, nem sempre essa associação estabelece novas concepções criativas para além das ações, objetos e discursos já estabelecidos nos meandros dessa subcultura. Ou seja, por mais que exista a particularidade do evento na maneira aleatória como são promovidos os encontros e as performatividades individuais, a maior parte do conjunto de objetos, discursos e ações se mantém vinculado à continuidade das convenções representativas e existenciais na configuração de unidade ao grupo. Inclusive, na lucratividade obtida diante de um contingente de consumidores alienados a própria condição do desejo.

Talvez, essa característica de alienação aos ritos do consumo para a constituição de identidades (coletivas e individuais) seja a principal forma de constituir sujeitos a partir da Modernidade. Justamente, nessa experiência de interação dos sujeitos com as coisas (objetos e discursos) estaria a viabilidade para o reconhecimento socioeconômico das representações divergentes da cisheterossexualidade. A própria representação definida por estabelecimentos comerciais e institucionais, ao reconhecer essa vivência estética e ética como modo de vida, torna legível a afirmação dessa experiência fora da condição precária em que se encontram as singularidades individualizadas pela sua condição dissidente. 
Ao mesmo tempo, essas vivências de atos, gestos e desejos dissidentes configuram-se por uma estética performativa mutável ao serem compartilhadas como identidade de grupo e combinadas com as particularidades de cada corpo, que integra essa multidão queer (Feria, 2014). Como se a experiência vivenciada, nesse caso, também servisse de referência para a reflexão estética e ética da existência para além das convenções identitárias (Sierra, Cesar, 2014).

Na relação de fatos apresentados nessa reflexão é possível compreender a associação entre o consumo de artigos materiais (envolvendo o espaço e os objetos) como meio de constituição de identidades, reforçadas pelas interações dissidentes de gênero e sexualidades. Assim, essa relação entre sujeito e objeto, na representação da subcultura do evento Folsom, está pautada pela condição de modernidade e da vida urbana da atualidade. Entretanto, podemos imaginar outras associações coletivas na busca pelo reconhecimento e aceitação social através de objetos e de prazeres, independente das relações vinculadas ao consumo?

Diante da condição de existência atual é difícil considerar vivências desvinculadas da estrutura complexa de fatores econômicos, sociais e culturais, que viabilizam as atividades hedonistas na medida em que podem ser exploradas como mais valia. Ou seja, qualquer experiência vivenciada fora da estrutura do mercado lucrativo, sem vinculo social e impacto nos meios culturais, tende a se tornar apenas uma perspectiva utópica.

Desse modo, para ilustrar a noção de um senso estético explorado no limite entre consumo e arte, e inspirada pela experiência vivenciada entre corpos e prazeres, talvez seja preciso considerar as experiências ocorridas em período anterior à condição da Modernidade. Para ilustrar essa noção, apresento outro evento visitado durante a pesquisa de campo e que traz uma referência estética na relação de prazeres carnais vinculados com a realidade.

No mesmo local onde ocorreu a festa Pig, no Alte Münze Berlin, também esteve presente a exibição Hieronymus Bosch Visions Alive, que tive a oportunidade de visitar em 30 de outubro de 2016, ou seja, por volta de seis semanas depois da festa relativa ao evento Folsom. As lembranças desta festa e as imagens do pintor medieval na exibição artística não apenas compartilharam as mesmas instalações, mas também, manifesta similaridades na representação do corpo e dos prazeres mundanos entre dissidência e normalidade.

A exibição multimídia de Bosch era composta por imagens de suas pinturas, ricamente coloridas e iluminadas, apresentadas em uma longa sequência de projeções sobre grandes 
superfícies do espaço expositivo. No contraste com a escuridão do ambiente interno do edifício, as imagens se destacavam, criando uma atmosfera de sonho embalada por trilha sonora na animação dos trabalhos do artista holandês. Hieronymus Bosch viveu entre 1450 e 1516 na cidade de 's-Hertogenbosch. Tornou-se um artista reconhecido tanto dentro do seu país quanto fora dele. Seu conjunto de obras está mais relacionado ao espírito religioso da Idade Média do que ao início do Renascimento. Bosch foi um artista nada convencional em sua época. Na avaliação das poucas obras com sua autoria reconhecida, Bosch é considerado isolado das inovações da arte renascentista (Nova Cultura, 1991). A interpretação do artista a partir de temas religiosos e metafísicos, portanto, envolve outros elementos e signos no processo criativo de suas pinturas, distintos de trabalhos de outros artistas nesse mesmo período. Bosch busca inspiração em gravuras, esculturas, elementos de magia, alquimia e astrologia, desenvolvendo um trabalho audacioso ao criar figuras bizarras para retratar a condição humana. Ao mesmo tempo, o corpo nu e a sexualidade também fazem parte de sua composição figurativa e fantástica. O que configura uma linha dual de interpretações. Para alguns críticos e especialistas do trabalho de Bosch, suas pinturas são carregadas de valores morais com o propósito de incitar o espectador à renúncia dos prazeres, enquanto outros interpretam suas figuras distorcidas como heréticas, pela própria indicação dos prazeres e pecados. De qualquer maneira, é inegável considerar o fator místico envolvendo o trabalho do artista, independente de seguir a ortodoxia ou a heresia. Esses arquétipos evocados em suas obras causam impactos e nutrem a imaginação entre diferentes temas envolvendo representações humanas nuas, pálidas e frágeis (Ribeiro, 2015; Nova Cultura, 1991).

A mais famosa obra de Hieronymus Bosch é O Jardim das delícias terrenas, pintado sobre a superfície de um retábulo, divido em três partes (tríptico). Nesta representação o artista ilustra a condenação humana provocada pela busca incansável dos prazeres mundanos. Os painéis laterais retratam o paraíso e o inferno, enquanto o central retrata, de maneira lúdica, ações e comportamentos de interação entre pessoas e seres oníricos. Esta produção é considerada um trabalho original na maneira como Bosch cria uma visão atraente e, ao mesmo tempo, diabólica para os pecados, alertando sobre o seu poder de sedução. Na riqueza dos detalhes e dos elementos simbólicos, Bosch explora elementos da natureza como fonte de tentação. $\mathrm{O}$ prazer sexual dos corpos no painel central torna-se, na lateral direita, o inferno ilustrado pelos exageros mundanos. Em destaque, no meio desse painel direito, está a imagem do homemovo, com o corpo oco, transformado em raízes e patas de porco. Atrás dele, em proporção 
menor de tamanho, uma figura humana sobe uma escada para entrar neste corpo, em suposta alusão ao pecado relativo à sodomia (Nova Cultura, 1991).

Ainda entre as especulações sobre a vida pouco documentada de Hieronymus Bosch, alguns pesquisadores consideram possível a sua participação na seita dos Irmãos e Irmãs do Livre Espírito, também conhecidos como adamitas. Para os adeptos e adeptas desta seita, a salvação da humanidade se daria com o retorno à pureza de Adão e Eva antes de serem expulsos do paraíso. Por isso, como parte dos ritos desta congregação renascentista, ao fim do cerimonial as luzes eram apagadas e o sexo seria praticado de maneira promíscua e ritualística entre homens e mulheres. Este estado paradisíaco de simulação das delícias era seguido de danças para a confraternização. Nenhuma prova, entretanto, confirma que Bosch fez parte desta congregação, mas algumas conjecturas apontam as imagens presentes no retábulo $\mathrm{O}$ jardim das delícias terrenas em referência a esses rituais de orgia. Enfim, seja enaltecendo ou condenando, o fato é que essas imagens se tornam ambíguas nas intepretações contemporâneas sobre a moralidade do corpo e no uso de objetos para saciar os desejos, inclusive, os sexuais (Ribeiro, 2015; Nova Cultura, 1991).

Desse modo, considero que a figura do homem ovo retratada em $\mathrm{O}$ jardim das delícias terrenas, de Hieronymus Bosch, é uma síntese da vinculação entre sujeito e objeto como entidade única na visão de um corpo apropriado pela sexualidade. Portanto, pensar na relação entre corpo e matéria através do prazer sexual é compreender que a busca do orgasmo, na verdade, se torna a busca por um momento efêmero de intenso prazer e resignação. Quem sabe, a busca por esse momento de prazer compartilhado acontece devido à impossibilidade do próprio corpo individualizado se tornar obra de arte diante das regulamentações sociais e dos condicionamentos materiais da atualidade - ou, ainda, devido à própria insatisfação recorrente das pessoas quando inseridas em processos de regulamentação, estejam motivadas pela razão ou pela espiritualidade.

\section{Considerações finais}

Em geral, são em práticas sexuais não hegemônicas, baseadas em fetiches, sozinhas ou em grupo, em áreas públicas, promíscuas e pornográficas que se promovem novas relações entre os sujeitos e destes com os objetos. Assim, dentro de processos de convivência e socialização, os corpos se adequam as condições precárias de representação social e redução dos riscos ao 
atenderem as demandas de consumo para compor suas representações sociais e minimizar as precariedades e exclusões.

Desse modo, nos exemplos apresentados nesse artigo, consideramos que a associação do corpo com objetos e a formação de corpos em aliança permitem conformar um lugar para a mutação do corpo abjeto em sua representação estética e ética de dissidência. Por outro lado, para subverter a ordem de regulamentação das sexualidades e no fomento dos diferentes modos de interação sociocultural, o corpo compreende o elemento central para a constituição de novas identidades na linha tênue que divide a performance artística das performatividades desviantes. Portanto, é nesse contexto de ambiguidade(s) que os corpos tornam-se apreensíveis pelo sistema de viabilidades econômicas na superestrutura da industrial cultural.

Do controle do corpo como fator de origem para novas sensações e da transformação da arte em mercadoria (Corbin, Courtine, Vigarello, 2009; Benjamin, 2000), também considero a amplitude de atuações artísticas no cotidiano de práticas e prazeres como meio de resistência política. Essa resistência surgiria na busca da transformação do corpo em obra de arte através do questionamento de sua condição de precariedades estéticas e existenciais. Entretanto, ao representar esse posicionamento de resistência artística o corpo precisa associar-se a outros corpos e objetos para garantir sua inclusão na vida social e no mercado de consumo.

Ao mesmo tempo em que o efeito da arte como resistência é suprimido pelos meios de produção e comunicação do capitalismo tardio também podemos considerar a autenticidade artística questionadora no sentido de revelar a ficção do mundo objetivo e técnico em nos tornar subordináveis aos meios de produção e consumo. Nesse sentido, a perda da pluralidade de ações e representações sociais no espaço público é uma tendência antidemocrática em restringir a presença do corpo singular e de sua estética de existência outsider. Muitas vezes, essas presenças são ignoradas em referência às ações de governabilidade arbitrária, em outras são coagidas a não exercer seu aparecimento público sob o risco do preconceito e da violência. Motivações e ações de moralidade justificadas em prol da segurança pública e contra atos ilícitos desses supostos sujeitos subversivos e, frequentemente, não representativos para o reconhecimento social (Duarte, 2001).

Entretanto, por mais que essas manifestações de singularidades de corpos e performatividades sejam, muitas vezes, antagônicas aos princípios morais e ideológicos predominantes, a ausência de uma política em favor da equidade expõe o estado de precariedades sociais na 
medida em que novas estéticas de existência são coagidas. Na verdade, trata-se de uma perspectiva de manutenção da estrutura capitalista e cisheteronormativa, em estabelecer hierarquias e regulamentações na esfera do espaço de aparecimento (Butler, 2018; Pallamin, 2010).

A partir dessa análise sobre eventos específicos, envolvendo subculturas de gênero e sexualidades dissidentes, considero que a expressão do corpo, das identidades e das sexualidades desviantes configura a possibilidade de constituição do sujeito contemporâneo como inspiração para uma nova estética de vida, ao romper os estados de resiliência social nas práticas hegemônicas de repressão para os desejos fixos e particulares. Quem sabe, as alianças com outros corpos e identidades possam estar nesses subterfúgios pautados pela experiência contemplativa e pelo desapego com objetos e territórios convencionais, na medida em que a ressignificação dos prazeres sexuais permita manter uma ética pós-identitária em respeito à singularidade do corpo e do desejo de cada pessoa. 
RELIES: Revista del Laboratorio Iberoamericano para el Estudio Sociohistórico de las Sexualidades. Número 3 (2020) 


\section{Referências bibliográficas}

Agamben, G. (2002). Homo Sacer: o poder soberano e a vida nua 1. Tradução Henrique Burigo. Belo Horizonte: Editora UFMG.

Arendt, H. (2007). A condição humana. Tradução Roberto Raposo; posfácio Celso Lafer. 10 ed. Rio de Janeiro: Forense Universitária.

Argan, G. C. (2005). História da arte como história da cidade. Tradução Pier Luigi Cabra. $5^{\mathrm{a}}$ ed. São Paulo: Martins Fontes.

Benjamin, W. (2000). A obra de arte na época de sua reprodutibilidade técnica. In: Adorno et. al. Teoria da Cultura de massa. Tradução Carlos Nelson Coutinho. São Paulo: Paz e Terra, p. 221-254.

Bento, B. (2006). A reinvenção do corpo: sexualidade e gênero na experiência transexual. Rio de Janeiro: Garamond.

Butler, J. (2018). Corpos em aliança e a política das ruas: notas para uma teoria performativa de assembleia. Tradução Fernanda Siqueira Miguens. $2^{\mathrm{a}}$ ed. Rio de Janeiro: Civilização Brasileira.

Cáceres-Feria, R. (2014). (Professor visitante CNPq/FAPESC; Universidade Pablo de Olavide, Departamento de Antropologia Social, Psicologia Básica e Saúde Pública. SevillaES). Aulas proferidas na disciplina de Tópicos Especiais em Sexualidades. Programa Interdisciplinar em Ciências Humanas da Universidade Federal de Santa Catarina. Florianópolis: UFSC. Agosto e setembro.

Corbin, A., Courtine, J. J., Vigarello, G.(Org.). (2009). História do corpo: As mutações do olhar. Tradução e revisão de Ephraim Ferreira Alves. 3. ed. Volume 3. Petrópolis, RJ: Vozes.

Duarte, R. A. P. (2001). Mundo "globalizado" e estetização da vida. In: Oliveira, N.; Zuin, A. Á.; Pucci, B. (Orgs.). Teoria crítica, estética e educação. $1^{\mathrm{a}}$ ed. Piracicaba - SP: UNIMEP, v. 1, p. 27-42.

Foucault, M. (2008). Nascimento da Biopolitica: curso dado no College de France (19781979); edição estabelecida por Michel Senellart; direção de François Ewald e Alessandro Fontana; tradução Eduardo Brandão; revisão de tradução Claudia Berliner. São Paulo: Martins Fontes.

Leite, M. (2014). Performatividade: inscrições, contextos, disseminações. Ponta Grossa: Práxis Educativa; v. 9, n. 1, p. 141-165.

Nova Cultura. (1991). Os grandes artistas. 2. ed. Vol. 6. Gótico e Renascimento. Giotto; Bosch; Van der Veyden, Coleção. São Paulo: Editora Nova Cultura.

Pallamin, V. (2010). Aspectos da relação entre o estético e o político em Jacques Rancière. Risco Revista De Pesquisa Em Arquitetura E Urbanismo (Online), (12): 6-16. Disponível em: https://doi.org/10.11606/issn.1984-4506.v0i12p6-16 Acesso em 21 nov. 2019.

Preciado, P. (2014). Manifesto contrassexual. Tradução de Maria Paula Gurgel Ribeiro. São Paulo: N-1 edições. 
Preciado, P. (2011). Multidões Queer: notas para uma política dos anormais. Tradução de Cleiton Zóia Münchow e Viviane Teixeira Silveira. Florianópolis: Revista Estudos Feministas; 19(1): 11-20.

Ribeiro, A. (2015). Guia grandes mestres da pintura. In: Base de dados Google Livros. 1. ed. São Paulo: Online. Disponível em: https://books.google.com.br/books?id=NEszDwAAQBAJ\&lpg=PA4\&dq=Guia\%20grandes\% 20mestres\%20da\%20pintura\&hl=pt-

BR\&pg $=\mathrm{PA} 4 \# \mathrm{v}=$ onepage $\& \mathrm{q}=\mathrm{Guia} \% 20$ grandes $\% 20$ mestres $\% 20 \mathrm{da} \% 20$ pintura $\& \mathrm{f}=$ false Acesso em 21 nov. 2019.

Sierra, J., César, M.R.A. (2014). Governamentalidade neoliberal e o desafio de uma ética/estética pós-identitária LGBT na educação. Educar em Revista. Curitiba: Editora UFPR, p. 35-51. Disponível em: http://www.scielo.br/scielo.php?script=sci_arttext\&pid=S0104$40602014000500004 \& \operatorname{lng}=\mathrm{en} \& \mathrm{nrm}=$ iso Acesso em 21 nov. 2019. 